\title{
La asolación del jaguar en el capital
}

\author{
Jonatan Job Morales Garcia \\ Investigador de Biofutura A.C., México \\ ORCID: https://orcid.org/0000-0001-9683-4074
}

Cita recomendada. MORALES GARCIA, J.J., La asolación del jaguar en el capital, dA. Derecho Animal (Forum of Animal Law Studies) 12/1 (2021). - DOI https://doi.org/10.5565/rev/da.553

\section{Resumen}

La asolación del jaguar comienza con la aparición y expansión del humano en América, creando una relación asimétrica entre estas dos especies de animales, preponderante al humano. La presente obra devela la opresión a la que ha sido sometido el jaguar, avasallado por la dominación humana y acentuada en la época prehispánica, colonial y la era del capital. El jaguar llevado al proceso de extinción es cosificado, se le mercantiliza y su existencia es reducida al fetichismo. Al jaguar se le oculta su ser, su racionalidad, su conciencia y sus capacidades cognitivas, para despojarlo de la vida, sin entender que cada individuo de esta especie se constituye como un ser en sí mismo; su vida libre, su dignidad, su pertenencia, su papel en el mundo y su vida son irremplazables. La conservación del jaguar requiere de un profundo cambio dialéctico de liberación dando paso a un nuevo paradigma de la conservación, resignificando al jaguar y la naturaleza, dejando atrás el pensamiento mercantilista, cosificador, utilitarista y colonizador.

Palabras clave: jaguar; conservación; cosificación; explotación; esclavitud; liberación.

\section{Abstract - The devastation of the jaguar in the capital}

The devastation of jaguars began with the appearance and spread of humans in America, creating an asymmetric relationship between these two animal species, with human dominance. This piece reveals the oppression suffered by jaguars, steamrolled by human domination accentuated in the pre-Hispanic age, colonial times and the time of capitalism. The jaguar is on the way to extinction; objectified, commoditized, and its existence reduced to fetish. It's being, its rationality, its consciousness and its cognitive capacities are hidden to deprive it of life, without the understanding that each individual of the species constitutes a being in itself. Its liberty, dignity, belonging, role in this world and its life are irreplaceable. The preservation of the jaguar requires a profound dialectical change towards liberation, opening the way for a new paradigm of conservation, reinstating meaning for jaguars and nature, leaving behind commercial, objectifying, utilitarian and colonial thinking.

Key words: jaguar; conservation, objectification; exploitation; slavery; liberation. 


\section{Introducción}

El jaguar (Panthera onca) es el felino de mayor tamaño en América, los registros más antiguos de la presencia de jaguar en el continente datan entre 820000 y 850000 años $\mathrm{AP}^{1}$. Durante los últimos 30000 años, una nueva especie comenzará a expandir su distribución en el continente y sostendrá una relación milenaria asociada principalmente a la competencia directa con el jaguar, esta especie es el humano.

El humano (Homo sapiens) es el animal dominante en este planeta ${ }^{2}$ y se ha convertido en el enemigo principal de la mayor parte de los organismos ${ }^{3}$. En su andar como especie, ha sido el motor de más de una extinción ${ }^{4}$, al final del pleistoceno realizó un asedio maximizado contra la megafauna; en este mismo periodo, propició el exterminio de todos los miembros del género Smilodon, y del género Panthera, además llevó a la extinción al Panthera onca mesembrina ${ }^{5}$. El impacto del humano sobre los demás seres con los que coexiste, ha sido tan grande que se ha establecido una nueva era: el antropoceno, esta era es el preámbulo de la sexta extinción masiva de especies ${ }^{6}$.

El jaguar, distribuido históricamente desde América del Norte hasta Suramérica, será perseguido por el humano hasta sistematizar su aniquilación, este fenómeno que abarca del Holoceno al Antropoceno ha llevado a este felino a un declive poblacional, que en la actualidad lo ha puesto en riesgo de extinción en prácticamente todas las naciones donde habita; por ejemplo, ha sido extirpado de El Salvador y Uruguay. Sudamérica mantiene el $93 \%$ del hábitat y potencial, seguido por Centroamérica (5.5\%) y México que representa el 1\% ${ }^{7}$. En este último, sus poblaciones se encuentran en grave riesgo, incluso ha sido extirpado prácticamente en un ámbito estatal en Tabasco, donde solo se cuenta con registros aislados ${ }^{8}$ y en los demás estados fuera de la península de Yucatán, sus poblaciones están igualmente amenazadas.

A nivel continental, los jaguares han desaparecido $55 \%$ de su rango histórico y la mayoría de las subpoblaciones están en peligro o en peligro crítico ${ }^{9}$, la Amazonia es el único baluarte que queda para la especie $^{10}$. En la actualidad, el tamaño poblacional del jaguar se estima en aproximadamente 64000 individuos, la subpoblación en el Amazonia comprende 57000 individuos, las 33 subpoblaciones restantes comprenden un total de 7000 individuos; $89.2 \%$ del total de jaguares se ubican en la Amazonia y solamente el $10 \%$ restante está distribuido en su ámbito de distribución continenta ${ }^{11}$, haciendo una comparación, podemos acércanos a la cifra poblacional teniendo como constantes la cifra territorial y la cifra poblacional; esto nos da una cifra histórica de la población de jaguar de 142222 ejemplares, donde el asedio ha eliminado 78222 jaguares aproximadamente.

${ }^{1}$ KURTÉN, B. The Pleistocene Jaguar in North America. Bulletin of the Florida State Museum, (Biological Series), 9 (1965), pp.215273.

2 EHRLICH P.R. y EHRLICH A.H. The Dominant Animal. Human Evolution and Environment, (Washington 2008).

${ }^{3}$ SOENTGEN J. Ecología del Miedo (Barcelona 2019) p.35.

${ }^{4}$ BARNOSKY, A.D., The late Pleistocene event as a paradigm for widespread mammal extinction en DONOVAN, STEPHEN K. (Ed.), Mass Extinctions: Processes and Evidence, (Columbia 1989), pp. 235-254.

${ }^{5}$ GONZÁLEZ MAYA J.F. Densidad, uso de hábitat y presas del jaguar (Panthera onca) y el conflicto con humanos en la región de Talamanca, Costa Rica (Costa Rica,2008) p.126.

${ }^{6}$ Véase LEAKEY, R. y LEWIN, R. La sexta extinción: el futuro de la vida y de la humanidad, (Barcelona 1997).

${ }^{7}$ SANDERSON E., REDFORE K., CHETKIEWICZ CH., MEDELLÍN R., RABINOWITZ A.,ROBINSON K. y TABER A. Planning to save species: the jaguar as model. Conservation Biology 16 (2002) pp. 58-72 y SANDERSON E., C. CHETKIEWICZ, R. MEDELLÍN, A. RABINOWITZ, K. REDFORD, J. ROBINSON Y A. TABER. Un análisis geográfico de estado de conservación y distribución de los jaguares a través de su área de distribución, en: El jaguar en el nuevo milenio (México 2002).

${ }^{8}$ HIDALGO-MIHART, MIRCEA G., CONTRERAS-MORENO, FERNANDO M., JESÚS DE LA CRUZ, ALEJANDRO, JUÁREZLÓPEZ, RUGIERI, VALERA-AGUILAR, DANIELA, PÉREZ-SOLANO, LUZ A., \& HERNÁNDEZ-LARA, CAROLINA. (2015). Registros recientes de jaguar en Tabasco, norte de Chiapas y oeste de Campeche, México. Revista mexicana de biodiversidad, 86, (2015) pp. 469-477.

${ }^{9}$ DE LA TORRE, J., GONZÁLEZ MAYA, J., ZARZA, H., CEBALLOS, G., y Medellín, R. The jaguar's spots are darker than they appear: Assessing the global conservation status of the jaguar Panthera onca en

https:/www.cambridge.org/core/journals/oryx/article/jaguars-spots-are-darker-than-they-appear-assessing the-global-conservationstatus-of-the-jaguar-panthera-onca/07988F672DDB1CD701370FC3E196199E\# [última consulta: 23 de noviembre 2020].

${ }^{10}$ SANDERSON, E.W., REDFORD, K.H., CHETKIEWICZ, C.B., MEDELLIN, R.A., RABINOWITZ, A.R., ROBINSON, J.G. \& TABER, A.B. Planning to save a species: the jaguar as a model. Conservation Biology, 16 (2002) pp. 58-72; SOLLMANN, R., TÔRRES, N.M. \& SILVEIRA, L. Jaguar conservation in Brazil: the role of protected areas. CAT News, Special Issue, (2008) pp.1520; DE OLIVEIRA, T.G., RAMALHO, E.E. \& DE PAULA, R.C. Red List assessment of the jaguar in Brazilian Amazonia. CAT News, Special Issue, (2012) pp.3-8.; TOBLER, M.W., CARRILLO-PERCASTEGUI, S.E., ZÚÑIIGA HARTLEY, A. \& POWELL, G.V.N. High jaguar densities and large population sizes in the core habitat of the southwestern Amazon. Biological Conservation, 159, (2013), pp. 375-381.

${ }^{11}$ DE LA TORRE, J., GONZÁlEZ MAYA, J., ZARZA, H., CEBALlOS, G., \& Medellín, R. (2018). The jaguar's spots are darker than they appear: Assessing the global conservation status of the jaguar Panthera onca en

https://www.cambridge.org/core/journals/oryx/article/jaguars-spots-are-darker-than-they-appear-assessing-the-global-conservationstatus-of-the-jaguar-panthera-onca/07988F672DDB1CD701370FC3E196199E\# [última consulta: 23 de noviembre 2020]. 
Desde una visión histórica, esta aniquilación sistematizada presenta puntos exponenciales del declive de la especie derivados de su cosificación y el conflicto que ha surgido en todo su espacio de distribución; estos elementos históricos se fusionan con elementos sociales, mercantiles y de dominación, consolidándose en la historia contemporánea principalmente en la era del capital, la era del imperio y el siglo XX. El constructo civilizatorio en su origen prehispánico de dominación está enraizado con la sistematización del asedio del jaguar ya sea en la destrucción de su hábitat o directamente propiciando el daño a los ejemplares de la especie. Las sociedades prehispánicas tuvieron un importante desarrollo que estaba encaminado a utilizar la naturaleza y realizar cambios de uso de suelo para adecuar la construcción de sus civilizaciones, sin embargo, algunas sociedades rebasaron los límites ecológicos; al destruir a la naturaleza, destruyeron su civilización. Tal es el caso de la cultura Maya, quienes tuvieron un colapso multifactorial de su civilización, y sin duda donde los factores ambientales fueron determinantes, principalmente una gran sequía, la disminución de la precipitación pluvial $^{12}$ y el secado de los cuerpos permanentes de agua, los cuales se transformaron en pantanos estacionales $^{13}$. Estos fenómenos estuvieron directamente asociados a la deforestación de carácter antrópico ${ }^{14}$ para el uso de estuco en sus construcciones arquitectónicas.

Partiendo de las dimensiones directas asociadas al asedio del jaguar en la época prehispánica, de acuerdo al Códice Mendoza y a la Matrícula de Tributos, este felino fue solicitado como tributo a manera de "trajes de guerrero" (confecciones con su piel), reduciéndolo por tanto, a un objeto cuya valía se asentaba en su uso como vestimenta. Esta cosificación fue tan importante que se consideró uno de los principales elementos tributarios de la Triple alianza ante los pueblos que dominaban. El Códice Mendoza es un documento pictográfico que nos muestra la materialización del jaguar, su importancia como mercancía y una de las formas de sistematización de su muerte. Dentro de los elementos que más se tributaban en Mesoamérica eran pieles curtidas y trajes confeccionados con partes de jaguar y plumas finas. De acuerdo al códice, aproximadamente $39.18 \%$ de las sociedades tributarias tenían entre los materiales a tributar partes de jaguar piel-. El sistema tributario fue un elemento de tasación y dominio de los mexicas ante los pueblos tributarios cuyo sistema se fue perfeccionando y consolidando conforme los fenómenos sociales.

En algunos puntos de la historia, el poderío mexica tuvo vínculos con el sur de Mesoamérica, actual Centroamérica ${ }^{15}$, por lo que tenían un dinamismo económico a gran escala en los sistemas de comercio y tributación. Dentro de las pictografías del códice se observa que existían áreas de tributación que comprendían diversos pueblos ${ }^{16} \mathrm{y}$ con el paso del tiempo, fue aumentando gradualmente el número de pueblos tributarios; en la primera parte del Códice Mendoza podemos apreciar el crecimiento exponencial del imperio mexica y el poderío de los Huey Tlahtoqueh, quienes consolidaron un crecimiento dinámico del imperio, llegando a tener en 1519, una colecta tributaria de por lo menos 61 provincias ${ }^{17}$ y más de 260 pueblos sujetos al pago de tributos $^{18}$. Conforme a las pictografías del códice encontramos aproximadamente 370 pueblos tributarios y por lo general, tenían conexión con espacios donde el jaguar se distribuía naturalmente, sin embargo, pueblos como Actopan y Coyoacán tenían que tributar con elementos basados en la piel de este felino. Debido a que en su territorio no se distribuía el jaguar de manera natural, se vieron orillados a mantener relaciones socioeconómicas con otras sociedades para cumplir con la ordenanza mexica.

Gran parte del dominio Mexica se ubica en la zona neotrópical y con espacios megadiversos de distribución histórica del jaguar. Conforme al apartado segundo de la historia dedicado al tributo del citado códice, podemos inferir que, por lo menos 145 pueblos tributarios tenían que dar elementos asociados al jaguar-mercancía como un bien tributario; 128 daban entre sus tributos una pieza de traje confeccionado con elementos del jaguar una vez al año, 9 sociedades tributarias daban 20 trajes de jaguar 1 vez al año, y 8

\footnotetext{
12 BRASWELL, G. E., GUNN, J. D., DOMÍNGUEZ-CARRASCO, M. R., FOLAN, W. J., FLETCHER, L., MORALES-LÓPEZ, A., y GLASCOK, M. D. Defining the Terminal Classic at Calakmul, Campeche en The Terminal Classic in the Maya Lowlands: Collapse, Transition, and Transformation, DEMAREST, A., RICE, P. M. y RICE, D. S. (eds.) (Colorado 2004) pp.190; GUNN, J.D., MATHENY, R.T. y FOLAN, W.J. Climate Change Studies in the Maya Area.

https://www.researchgate.net/publication/231980445_Climate-Change_Studies_in_the_Maya_Area_[Última consulta: 23 de noviembre 2020].

${ }^{13}$ DUNNING, N. P. Birth and Death of Waters: Environmental Change, Adaptation and Symbolism in the Southern Maya Lowlands en Espacios mayas: usos, representaciones, creencias, (México 2003), pp. 49-76.

${ }^{14}$ GUNN, J., FOSS J.F., W.J., M. R. DOMÍNGUEZ-CARRASCO, M.R., y FAUST B.B., Bajo Sediments and the Hydraulic System of Calakmul, Campeche, México. https://www.cambridge.org/core/journals/ancient-mesoamerica/article/abs/bajo-sediments-and-thehydraulic-system-of-calakmul-campeche-mexico/983A4CF66394721B60708A22E436BF2A. [Última consulata 23 de noviembre 2020].

${ }^{15}$ LEÓN-PORTILLA, M. Religión de los nicaraos.Análisis y comparación de tradiciones culturales nahuas. (México 1972), p. 108.

${ }^{16}$ DE ROJAS J.L. Los libros pictográficos de tributos: Códice Mendoza y Matrícula de tributos. Estudios de historia social y económica de América, 12 (1995), pp. 651-662.

17 CARRASCO P. Estructura político-territorial del imperio tenochca. La Triple Alianza de Tenochtitlán, Tetzcoco y Tlacopan, (México 1996);BARLOW, R.H.La extensión del imperio de los culhua mexica en Obra histórico-antropológica (México 2005); HASSIG R. Aztec Warfare. Imperial Expansion and Political Control (University of Oklahoma Press 1995).

${ }^{18}$ GALINDO Y VILLA, J. Códice Mendoza (México 1988).

50 Derecho Animal. Forum of Animal Law Studies, vol. 12/1
} 
sociedades daban 40 pieles de este felino cada 6 meses. Esto suma un total de 308 vestimentas de jaguar aunado que para la construcción de los trajes se debían de usar más de una sola piel por traje- y 640 pieles de tributación al año. El tributo era una de las tres formas más utilizadas de relaciones socioeconómicas por los mexicas, estas prácticas se relacionaban entre si en varios niveles de organización y eran el tributo, tráfico exterior y mercados ${ }^{19}$, por lo que los datos presentados representan solamente una dinámica parcial del comercio del jaguar-mercancía en esta época.

En los espacios prehispánicos donde se va a distribuir el jaguar en Suramérica el felino no será parte de tributaciones de las civilizaciones dominantes ${ }^{20}$, para el caso peruano, el tributo se instauró hasta la época colonial, pues las obligaciones de los grupos incas hacia el Inca y/o el Estado incaico estaban representados por la mita y el repartimiento de mercancías donde no figuraba este felino, para el caso colombiano, la definición sobre la imposición del tributo también es aceptada como válida. Es decir, el sistema de tributos fue una empresa colonial y no existe un parangón con la realidad precolombina de los diversos pueblos que desarrollaron sus culturas en este territorio. Lo que sí podemos encontrar en ese espacio es una especie de redistribución de la naturaleza de acuerdo a un sistema de organización centralizado.

En algunas culturas de Mesoamérica, los Andes, la Amazonía y en general en Sudamérica, el felino (jaguar o puma) es el depredador cuyas fauces reaparecen constantemente en las caras divinas ${ }^{21}$. Desde épocas prehispánicas en esta zona sur existió un sistema simbólico del jaguar expresado en manifestaciones ${ }^{22}$ materiales ${ }^{23}$ e inmateriales ${ }^{24}$; en algunos espacios se conjugaban imbricaciones entre el chamanismo, el jaguar y las drogas ${ }^{25}$. Estas manifestaciones del jaguar estaban representadas con mayor intensidad en las culturas formativas regionales a lo largo de los Andes y áreas periféricas ${ }^{26}$. Los motivos más tempranos que se conocen de felinos datan de cerca de 2000 años A.C. y fueron encontrados en la Cueva de las Lechuzas en las laderas de la Montaña Occidental de los Andes Centrales Peruanos cerca de Pucallpa ${ }^{27}$. Pese a esta gran riqueza cultural, estas prácticas no van a formar parte del núcleo duro de estas sociedades, tampoco el jaguar va a ser un elemento que se incorpore en el ethos prehispánico suramericano ${ }^{28}$.

En la época colonial, el dominio de la corona española, representado por la iglesia y los conquistadores posicionaron al indio bajo el señorío del monarca, obligado a dar presentes y tributos, esta relación fue la representación clásica medieval de la sumisión. En el colonialismo, los españoles consideraron el oro como la principal riqueza de la Nueva España, en un principio, el despojo se basó en la extracción del metal y los repartimientos de indígenas, éstos últimos fueron sometidos a un sistema de explotación y una semiesclavitud, quedando sujetos al vasallaje español ${ }^{29}$. Pese a que el jaguar se tornó un elemento circunstancial de la relación mercancía-tributo y de los intereses de los dominadores, el felino será aun comerciado y extraído de su hábitat ${ }^{30}$ por lo que la aniquilación siguió y se potenció con el uso de mecanismos armamentísticos bélicos, incluido el uso de perros de cacería, este punto de cacería exponencial será mencionada por Humboldt años después, quien mencionaba que, a principios de 1800, se exportaban 2000 pieles de jaguar por año desde el puerto de Montevideo ${ }^{31}$ (donde actualmente el jaguar está extinto) en este periodo aproximadamente 4000 jaguares eran cazados al año para ser exportados a Europa ${ }^{32}$.

\footnotetext{
${ }^{19}$ FRANCES, B. Tres formas de intercambio en la economía azteca en Economía, política e ideología en el México Prehispánico (México 1980).

${ }^{20}$ Véase Fundación Misión Colombia, Historia de Bogotá. Conquista y Colonia, Tomo I (Colombia 1989) p.48.

${ }^{21}$ LÓPEZ-AUSTIN, A., MILLONES, L. Dioses del norte, dioses del sur (México 2007).

${ }^{22}$ Véase LEVI-STRAUSS, C. Mitologías. Lo crudo y lo cocido (México 1968); REICHEL-DOLMATOFF, G. El chamán y el jaguar: estudio de las drogas narcóticas entre los indios de Colombia (Bogotá 1978); REICHEL-DOLMATOFF,G. Colombia indígena, periodo prehispánico en Nueva Historia de Colombia (Bogotá 1971) pp.21-67.

${ }^{23}$ Véase MEGGERS, B. J., EVANS, C. Y ESTRADA E. Early Formative period of coastal Ecuador; the Valdivia and Machalilla phase, en Smithsonian Contributions to Anthropology, 1 (Washington D.C. 1965)

JUNIUS B. BIRD. Pre-ceramic art from huaca prieta, Chicama Valley, en Ñawpa Pacha: Journal of Andean Archaeology, 1 (1963), pp. 29-34; REICHEL-DOLMATOFF, G. Excavaciones arqueológicas en Puerto Hormiga: Departamento de Bolívar. Tomo 2 (Colombia 1965) p.78 y ss.

${ }^{24}$ La UNESCO inscribió en 2011 en la Lista Representativa del Patrimonio Cultural Inmaterial de la Humanidad a "Los conocimientos tradicionales de los chamanes jaguares de Yuruparí" en Colombia.

${ }^{25}$ REICHEL-DOLMATOFF G. Amazonian Cosmos (Chicago 1971); REICHEL-DOLMATOFF, G. El chamán y el jaguar: estudio de las drogas narcóticas entre los indios de Colombia (México 1978).

${ }^{26}$ DILLEHAY T.D., y KAULICKE, P., Aproximación metodológica: El comportamiento del jaguar y la organización socio-espacial humana en http://sedici.unlp.edu.ar/bitstream/handle/10915/25133/Documento_completo.pdf?sequence=1 [Última consulta: 23 de noviembre 2020].

${ }^{27}$ Véase LATHRAP D.W., The Upper Amazon (Ancient people \& places) (1970 Londres).

${ }^{28}$ En el caso de la cultura incaica primaron otros elementos de la naturaleza. Aunque en el panteón andino figuras como la huaca de la luna con atributos representativos del felino, están presentes, éstos elementos no sobrepasan el ámbito de lo secundario.

${ }^{29}$ Véase ZAVALA, S. Los intereses particulares en la conquista de la Nueva España (México 1964).

${ }^{30}$ Véase DÍAZ DEL CASTILLO, B. Historia verdadera de la Conquista de la Nueva España (Barcelona 2011).

${ }^{31}$ CABRERA, A. y YEPES, J.Mamíferos Sud-americanos. Historia Natural Ediar (Buenos Aires 1940), p. 370 y ss.

${ }^{32}$ GUGGISBERG, C.A.W. Wild cats of the world (New York, 1975) p.89.
} 
En la historia contemporánea comprendida en la era del imperio, la era del capital y el siglo XX, el asedio se potenciará a niveles críticos derivado del uso de pieles en la industria de la moda y la expansión de la ganadería rural: aproximadamente se extraían de la Amazonía brasileña hasta 15000 jaguares y 80000 ocelotes cada año a finales de la década de 1960 y $1970^{33}$ Las estimaciones de las importaciones anuales en los Estados Unidos y Europa en el período, indican que anualmente llegaban al mercado más de 15000 pieles de jaguares y 200000 ocelotes donde se incluían otras especie similares de menor tamaño, como el tigrillo o el jaguarundi ${ }^{34}$. En México 1300 pieles de jaguar y 15000 de ocelote y tigrillo, fueron exportadas legalmente a Estados Unidos de América entre 1968 y $1970^{35}$ (Figura 1). Esta visión de aniquilación representa la cúspide del asedio del jaguar, si bien el capitalismo no es el culpable de la explotación de los animales no humanos, este sistema va a intensificar y a fortalecer la reducción de los animales y será parteaguas en la sexta extinción masiva de especies.

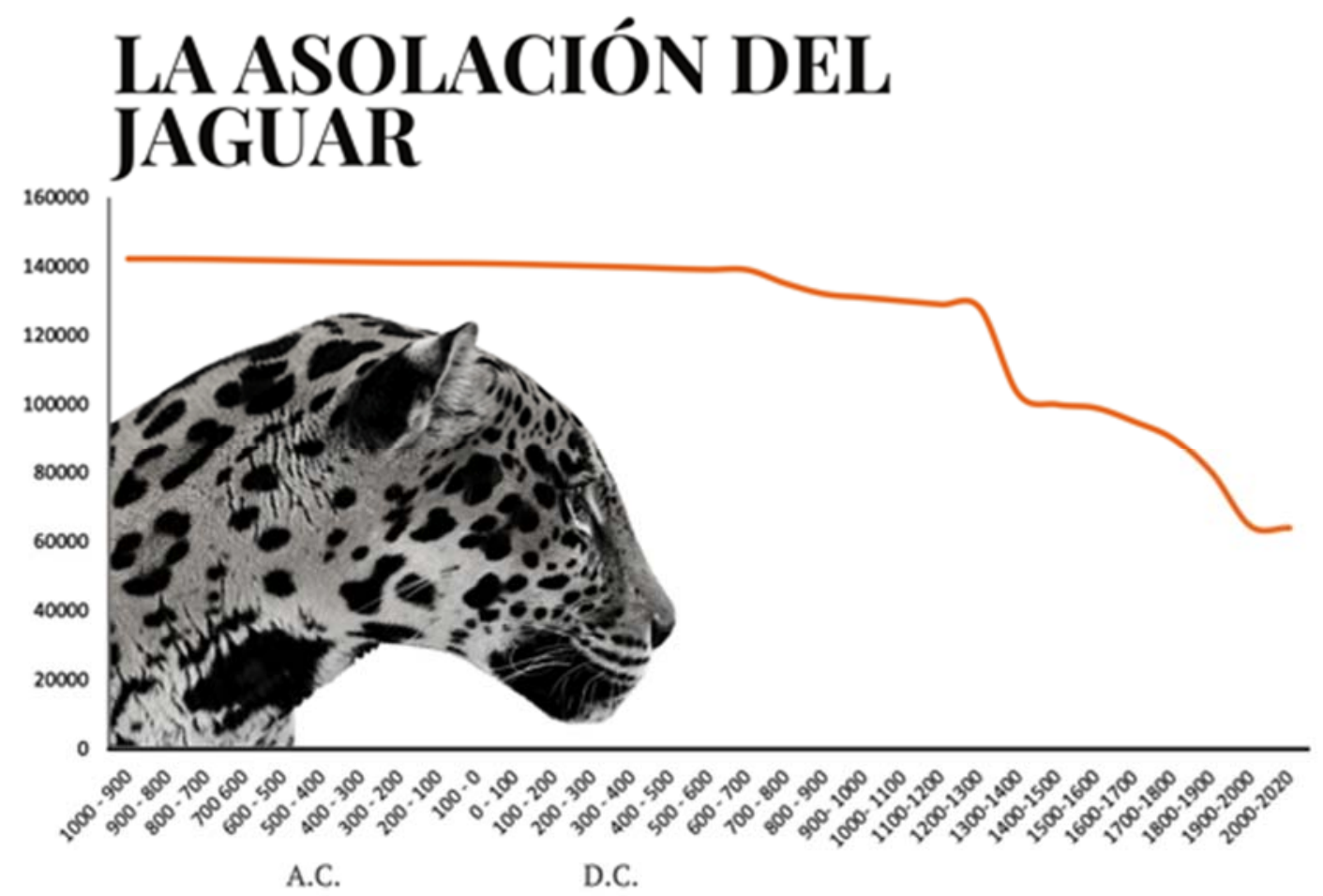

Figura 1. El decrecimiento del jaguar se asocia a factores civilizatorios de dominación. Los puntos exponenciales son la época prehispánica, colonial y la era del capital.

Fuente: Autoría propia

Las sociedades prehispánicas tenían una visión multidimensional que, si bien utilizaron al jaguar como una mercancía, también tenían una gama amplia de simbolismos, cultos y prácticas culturales asociados a él.

El capitalismo es un elemento sociocultural que ha maximizado el encubierto de la naturaleza, reduciéndola a una visión hegemónica de cosa-mercancía. El capitalismo tiene un origen basado en la esclavitud y aniquilación de los animales; basta tener un acercamiento al significado para dar cuenta que el término capitalismo refiere al latín caput, capita, refiriéndose a las cabezas de ganado ${ }^{36}$, a las posesiones. El daño, la cosificación, esclavitud y explotación ya están inscritos en su nombre.

\section{Aproximación etológica}

Todos los organismos del planeta poseen cromosomas en los que se almacena material genético transmitido de generación en generación ${ }^{37}$ dando con el paso del tiempo, una gran diversidad de

\footnotetext{
${ }^{33}$ SMITH, N.J.H. Spotted cats and the Amazon skin trade, en Oryx 13 (1976) pp. 362-371.

${ }^{34}$ FITZGERALD, S. International Wildlife Trade: Whose Buisiness is It? (Washington DC 1989) p. 333; WWF-US.; Kristin Nowell \& Peter Jackson. Wild Cats: Status Survey and Conservation Action Plan. International Union for Conservation of Nature and Natural Resources, Gland and Cambridge (Cambridge 1996) p. 223.

${ }^{35}$ CEBAllos G., LIST R., MEDELLÍN R., BONACIC C. y PACHECO J. Los Felinos de América. Cazadores sorprendentes (México 2010) p. 157.

${ }^{36}$ NOVAK, M. El capitalismo correctamente entendido la vision del humanismo cristiano, en Faith and Reason, 17 (1991), p. 18, https://www.cepchile.cl/cep/estudios-publicos/n-31-a-la-60/estudios-publicos-n-48/el-capitalismo-correctamente-entendido-lavision-del-humanismo-cristiano [Última consulta: 22 de noviembre 2020].

${ }^{37}$ Veáse SAGAN, C. Los dragones del eden. Especulaciones sobre la evolución de la inteligencia humana (Barcelona 2002).

52 Derecho Animal. Forum of Animal Law Studies, vol. 12/1
} 
manifestaciones de la vida con sistemas complejos. Dentro de estos grupos, algunos organismos animales sobresalen por su dimensión cognoscitiva; si bien están conformados de un gran cúmulo de protoplasma substrato material en el que se desarrollan los fenómenos vitales de los diversos organismos- ${ }^{38}$ algunos animales van a contar con una cognición compleja y alta inteligencia que ha evolucionado varias veces, de forma independiente ${ }^{39}$.

En la complejidad presente en la biodiversidad, algunos animales -donde se incluyen los humanos generalmente- poseen como característica notables facultades cognoscitivas y un elevado índice de percepción, posicionándose como seres consientes con una gran variedad de estados mentales que representan sus propias situaciones, inteligencia y tendrán, en algunos casos, autoconciencia, lo que implica ser consciente de las bases que conforman nuestras creencias y actos, esto es el origen de la razón ${ }^{40}$. Estos seres tienen empatía, toman decisiones, son en general seres consientes por lo que su vida libre, su dignidad, su pertenencia y su papel en el desarrollo de la vida natural es irremplazable, perderlos es perdernos a nosotros mismos ${ }^{41}$. Aunque estas habilidades complejas se han demostrado en un principio en vertebrados de cerebro grande, existe evidencia que demuestra que algunos cefalópodos realizan sofisticados actos de comportamiento flexible que los ha llevado a postularlos como seres de cognición compleja ${ }^{42}$. La evidencia científica demuestra que muchos animales poseen cognición compleja ${ }^{43}$, y diversas especies de este reino cuentan con habilidades complejas cognoscitivas como el razonamiento causal, la imaginación, apreciación del tiempo, la atribución mental, entre otros.

En diversas manifestaciones de vida del reino animal existen seres con un cúmulo mental de elementos asociados y diferenciados por los procesos evolutivos y de adaptación, pero similares en su base. En este grupo pueden incluirse algunos vertebrados pertenecientes a los ordenes de los mamíferos, las aves, algunos reptiles, anfibios e incluso en algunos invertebrados que son especies distantes evolutivamente como los cefalópodos ${ }^{44}$. La ciencia demuestra que el mecanicismo animal ${ }^{45}$, la consideración de irracionales ${ }^{46} \mathrm{o}$ de bestias brutas a los animales se sustentan en un error.

Charles Darwin delimitó que cualquier animal dotado de instintos sociales bien marcados, incluido el cariño parental y filial, inevitablemente adquiriría un sentido moral o conciencia tan pronto como sus facultades intelectuales hayan logrado un desarrollo tan elevado. Un rasgo característico de los procesos cognoscitivos avanzados es la empatía animal; todos los mamíferos son sensibles a las emociones ajenas y reaccionan ante los necesitados, esta empatía requiere conciencia del otro y sensibilidad a las necesidades ajenas $^{47}$. Estas características las presenta el jaguar, que es un animal que se incluye en el filo de los cordados, sus características lo posicionan en la clase de los mamíferos de la orden carnívora, es parte de la familia Felidae, con la subfamilia Pantherinae ${ }^{48}$.

En general, los estudios sobre cognición de felinos silvestres son escasos ${ }^{49}$, sin embargo, podemos tener un acercamiento desde una visión comparativa con los demás animales; la ausencia de evidencia no es evidencia de ausencia, los estudios son exhaustivos y permiten un acercamiento a la cognición del jaguar. Desde una analogía podemos aseverar que este felino es un animal con sistemas complejos cognoscitivos, como animal desde dimensiones individuales es un ser con consciencia, sus circuitos cerebrales, sus sustratos

\footnotetext{
${ }^{38}$ Veáse OPARÍN, A. El origen de la vida (Madrid 1984).

${ }^{39} \mathrm{ROTH}, \mathrm{G}$. Convergent evolution of complex brains and high intelligence. Philosophical Transactions of the Royal Society, en https://www.ncbi.nlm.nih.gov/pmc/articles/PMC4650126/ [Última consulta: 23 de noviembre 2020].

${ }^{40}$ DE WAAL, F. Primates y filósofos. La evolución de la moral del simio al hombre (Barcelona 2007) p. 147.

${ }^{41}$ DE WAAL, F. El mono que llevamos dentro (Barcelona 2007) p. 240.

${ }^{42}$ AMODIO, P. Octopus intelligence: the importance of being agnostic, en Animal Sentience 26 (2019) 20; AMODIO, P., BOECKLE, M., SCHNELL, A. K., OSTOJI, L., FIORITO, G. \& CLAYTON, N. S. Grow smart and die young: why did cephalopods evolve intelligence?, en Trends in Ecology and Evolution 34 (2019) pp. 45-56.; AMODIO, P., BOECKLE, M., SCHNELL, A. K., OSTOJI, L., FIORITO, G. \& CLAYTON, N. S., Shell loss in cephalopods: trigger for, or by-product of, the evolution of intelligence? A reply to Mollo et al, en Trends in Ecology and Evolution, 34 (2019), pp. 690-692.

${ }^{43}$ Véase EMERY, N. J. \& CLAYTON, N. S. The mentality of crows: convergent evolution of intelligence in corvids and apes, en Science 306 (2004), pp.1903-1907.

44 Véase WELLS, M. J. Octopus: Physiology and Behaviour of an Advanced Invertebrate (London 1978); ABBOTT, N., WILLIAMSON, R. \& MADDOCK, L. Cephalopod Neurobiology: Neuroscience Studies in Squid, Octopus, and Cuttlefish (Oxford 1995); YANG, T. I. \& CHIAO, C. Number sense and state-dependent valuation in cuttlefish, en Proceedings of the Royal Society B: Biological Sciences 283 (2016); JOZET-ALVES, C., BERTIN, M. \& CLAYTON, N. S. Evidence of episodic-like memory in cuttlefish, en Current Biology 23 (2013), R1033-R1035.

${ }^{45}$ Veáse DESCARTES, R. El discurso del método (Madrid 2010) pp. 67 y ss.

${ }^{46}$ CARRUTHERS, P. La cuestión de los animales. Teoría de la moral aplicada (Cambridge 1995).

${ }^{47}$ DE WAAL, F. El Bonobo y los diez mandamientos (México 2014) p.17.

${ }^{48}$ SEYMOUR, L. Panthera onca. Mammalian species, 340 (1989) pp. 1-9.

${ }^{49}$ BORREGO, N. Big cats as a model system for the study of the evolution of intelligence, en

https://www.sciencedirect.com/science/article/abs/pii/S0376635716302960 [Última consulta: 23 de noviembre 2020].
} 
neurológicos y los procesos cognitivos ${ }^{50}$ le permiten una amplitud de experiencias, percepciones, emociones y racionalización de su mundo, constituyendo en cada ejemplar un ser en sí mismo.

Una visión etológica comparativa permite entender que cuanto más complejos y diferenciados son los órganos de construcción análoga y destinados a cumplir con la misma función, más derecho nos asiste para agruparlos en la misma concepción funcional y designarlos con el mismo nombre, por muy diferente que sea su origen filogenético ${ }^{51}$. Entendiendo lo anterior, el cerebro, el sistema nervioso central y el conjunto de órganos asociados a los procesos cognitivos y sensoriales tendrán una designación, concepción, y una organización esencialmente similar funcional ${ }^{52}$ en el animal humano y en el animal no humano como lo es el jaguar.

\section{El asedio del jaguar en la modernidad}

Desde enfoques ecológicos, el humano al igual que el jaguar son animales que se ubican en la cima trófica $^{53}$. Durante milenios estos dos animales han generado diversas interacciones interespecíficas ${ }^{54}$, consolidando de manera general una relación de competencia asimétrica preponderante hacia el humano, esta relación ha posicionado al jaguar en una dialéctica hacia lo otro, el ser con el que se compite, una amenaza ${ }^{55}$, por lo que, como especie, hemos considerado generalmente a este felino como un adversario, eliminando la compasión en su aniquilación.

Estas conductas antrópicas son resultado de la guerra milenaria del humano contra el jaguar y los animales; esta lucha tendrá un resultado catastrófico para los demás animales ya que se van a esclavizar y explotar para reducirlos y dimensionarlos en torno a su valor de uso y a su valor de cambio, y a los que no, o que atenten contra los intereses humanos, serán aniquilados. En las zonas rurales donde aún no se ha mercantilizado a este felino y su presencia se torna antiproductiva a los intereses acumulativos de las personas $^{56}$, el asedio del jaguar se asociará a la frustración de aquellos que no ejercen su poder ante sus dominadores, y se transformarán en dominadores de este felino y la naturaleza, obteniendo la satisfacción de saber que son diferentes al tratar con brutalidad y dañar al otro ${ }^{57}$.

El jaguar en la historia moderna va a estar sumergido de manera acumulativa en una economía global basada en el capitalismo, y cuando se torne anti productivo, será eliminado. El fetichismo de la mercancía felino-objeto será la cúspide de la dominación y miseria del jaguar. En la actualidad existe una internalización profunda de las relaciones de dominación hacia el jaguar que han consolidado un referente ausente que refleja los procesos estructurales de ocultamiento de la alienación y cosificación del sujeto-jaguar para visibilizar la mercancía-jaguar que será el producto fabricado como intercambiable y puesto en el mercado ${ }^{58}$ para así, eliminar su historia, su ser y su identidad.

La relación humano-jaguar en un primer momento entrará en esta dominación donde al considerarse un elemento conflictual, por atentar contra los intereses humanos se le privará de la vida, y cuando se le mercantiliza para obtener de él, o sus partes, una ganancia, el jaguar entrará en el dominio del capital.

La relación humano-jaguar basada en el dominio y el ejercicio del poder sobre este felino y la naturaleza es compleja. El humano dimensiona al poder como una cualidad de aniquilación que asola la vida animal y cimienta la moral de las sociedades hacia la reducción del jaguar como una cosa susceptible de explotación desde dimensiones mercantiles; este modelo reduccionista del jaguar se cimienta en la conquista y se consolida en la historia contemporánea principalmente en la era del capital, la era del imperio y el siglo XX, como ya hemos dicho.

El capitalismo llegó al continente americano desde fuera y como conquista, adoptando de inicio la

\footnotetext{
50 Véase la Declaración Sobre la conciencia de Cambridge. https://www.animal-ethics.org/declaracion-consciencia-cambridge/ [Última consulta: 23 de noviembre 2020].

${ }^{51}$ Véase LORENZ, K. Sobre la agresión: el pretendido mal (Madrid 1972) p.233 y ss.

${ }^{52}$ Véase DE WAAL, F. ¿Tenemos suficiente inteligencia para entender la inteligencia de los animales? (Madrid 2016) p.146 y ss.

${ }^{53}$ CEBALLOS G., CHÁVEZ C., RIVERA A. y MANTEROLA C. Tamaño poblacional y conservación del jaguar en la reserva de la biosfera de Calakmul, Campeche, México en El jaguar en el nuevo milenio (México 2002) pp.37.

${ }^{54}$ MORALES, A. y MORALES J. Justicia y vida silvestre: dos estudios de caso sobre ilícitos ambientales del orden federal asociados al jaguar en México, en https://revistes.uab.cat/da/article/view/v9-n3-morales [Última consulta: 23 de noviembre 2020].

55 Véase GERRITSEN P. y ESPARZA J. Percepciones y opiniones de campesinos y técnicos en torno al jaguar y su conservación en la Reserva de la Biosfera Sierra de Manantlán, Occidente de México, en Áreas Naturales Protegidas, Scripta, 5 (2019) pp. 19-38.

${ }^{56} \mathrm{El} \mathrm{jaguar}$ en relación al capital también llega a considerarse antagonista cuando no es parte del sistema capital de acumulación y despojo, un ejemplo se da cuando este felino está libre y ataca para alimentarse de animales esclavizados mediante proceso de domesticación para el consumo humano (p.e. vacas), este acto se visibiliza como un ataque al sistema de producción y acumulación del propietario y se le persigue por ello, en esta visión capitalista, el jaguar será conceptualizado como un elemento carente de valor económico y por lo tanto, despreciable.

${ }^{57}$ Véase la obra de MARX, C. El Capital. Tomo I (México 2015).

${ }^{58}$ Véase DUSSEL, E.16 tesis de economía política. Interpretación filosófica (México 2014) pp. 39 y ss.

54 Derecho Animal. Forum of Animal Law Studies, vol. 12/1
} 
forma colonial; un paradigma perverso que a la vez responde a la lógica expansiva generando un sistema que produce y reproduce relaciones serviles y esclavistas, devorando el planeta, asimilando cuanto le sirve y eliminando el resto ${ }^{59}$. En la lista de elementos destrozados por el capital, la naturaleza, al representar una de las principales fuentes de la riqueza ${ }^{60}$ será esquilmada hasta niveles alarmantes, aniquilando millones de animales, siendo los grandes carnívoros uno de los principales despojos naturales por el capital. En la historia moderna, el jaguar será cosificado y su existencia será reducida de acuerdo al fetichismo de la mercancía en valor de uso, su posterior valor de cambio y sus servicios en una dominación integral. Al someterse al modo de producción, el jaguar será tratado como mercancía y no como lo que en realidad es, esto dará como resultado una explotación diversificada como fuente del capital, cuyo fin directo es la creciente apropiación de la riqueza abstracta, el movimiento incansable de ganar, un afán absoluto de enriquecimiento, una inextinguible pasión por la ganancia, la auri sacra fames ${ }^{61}$.

El jaguar-mercancía-servicio solamente valdrá por la ganancia, y esta se producirá a través de diversas formas de esclavitud del felino, redimensionando el ser, la esencia y el concepto del jaguar, -que desde enfoques científicos es un animal sintiente con una carga simbólica cultural del orígenes prehispánicos ${ }^{62}{ }^{-}$. Esta transformación expulsará los elementos ontológicos y la memoria de las sociedades rurales no rentables para reducirlo en un elemento del capital natural, expresándose en una gran gama de productos que dicta la sociedad de consumo actual, siendo los principales -no limitativos- los siguientes: 1) mascota, 2) elemento de exhibición, 3) colecciones privadas, 4) espectáculos, 5) medicina tradicional, 6) rituales, 7) ornato, 8) cacería y 9) vestimenta (Figura 2). Esta sociedad de consumo tendrá un límite por el peligro de extinción de esta especie, por lo que establecerá mecanismos a través de la racionalidad al servicio del capital para perpetuar la dominación a través de la industrialización del mercado de jaguares para la sociedad de consumo con determinados estándares y medidas. El jaguar ahora será un producto, algo que necesita ser cosechado en granjas y que tendrá un precio de mercado, generándose así la escuela arcaica de la conservación al servicio del capital y el dominio.

Entre las formas de explotación de este animal, a finales del siglo XX, se le tomará especial importancia por el 10) servicio que da al humano a través de los servicios ambientales (Figura 2); esto se asocia a la condición del sistema abierto de dominio del capital ya que este sistema fluye libremente en la acumulación y la ganancia, si bien parecería que esta visión permea en la actualidad en algunas sociedades al considerar al jaguar una especie en riesgo y valorizar su importancia ambiental y cultural, en realidad esto es simplemente una forma de explotación ya que se transforma en una ganancia-beneficio para el capital a fin de que persista el dominio a largo plazo. Conservar especies en peligro de extinción sólo se da por que el capital se ve obligado a tomar este giro, debido a la flexibilidad de este sistema, incluso en especies en peligro de extinción, el asedio se dará bajo el termino mercantil del aprovechamiento sustentable, que es la forma en que el capital pueda seguir controlando la vida de este felino por la eternidad.

Uno de los felinos silvestres que ha sido víctima del aprovechamiento sustentable en un giro comercial, capitalista y exponencial es el tigre (Panthera tigris), que dentro de las estrategias para reducir su comercio ilegal desde la (i)rracionalidad capitalista, han regulado comercialmente en algunos países su mercantilización, esto tiene como consecuencia que existan entre 150000 y 200000 tigres en cautiverio alrededor del mundo ${ }^{63}$. Estos animales en el racionalismo capital han sido producidos en granjas de tigres para satisfacer la voracidad de las sociedades de consumo que utilizan los productos siguientes: yesos, vino de huesos, pieles, polvo de huesos, vino de pene, órganos, gelatina de huesos, vino de corazón ${ }^{64}$, dientes, bigotes, huesos para ornamentación y como mascotas. Estas estrategias de conservación al servicio del capital y las sociedades de consumo son la miseria de miles tigres esclavizados.

\footnotetext{
${ }^{59}$ BARTRA A. El hombre de hierro. Límites sociales y naturales del capital en la perspectiva de la Gran Crisis (México 2014) p. 47 y ss.

${ }^{60}$ Veáse MARX C. El Capital. (México 2015) p. 141 y ss.

${ }^{61}$ Ibíd.

${ }^{62}$ MORALES, A. y MORALES, J. Patrimonio cultural y biodiversidad; el caso del jaguar mexicano, en Boletin Mexicano de Derecho Comparado (2019) pp. 973-999, https://revistas.juridicas.unam.mx/index.php/derecho-comparado/article/view/13664/15002>. [Última consulta: 26 nov. 2020].

${ }^{63}$ LUO S.J., JOHNSON W.E.,MARTENSON J.,ANTUNES A., MARTELLI P., UPHYRKINA O.,TRAYLOR-HOLZER K., SMITH J.L.D., y O'BRIEN S.J. Subspecies Genetic Assignments of Worldwide Captive Tigers Increase Conservation Value of Captive Populations, en https://www.sciencedirect.com/science/article/pii/S096098220800434X [Última consulta: 23 de noviembre 2020].

${ }^{64}$ Véase GRATWICKE B., MILlS J., DUTTON A., GABRIEL G., LONG B., SEIDENSTICKER J., WRIGHT B., YOU W., ZHANG L. Attitudes Toward Consumption and Conservation of Tigers in China, en Plos one. https://pubmed.ncbi.nlm.nih.gov/18596926/ [Última consulta: 23 de noviembre 2020].
} 


\section{TRANSFORMACIÓN DEL JAGUAR EN EL CAPITAL}

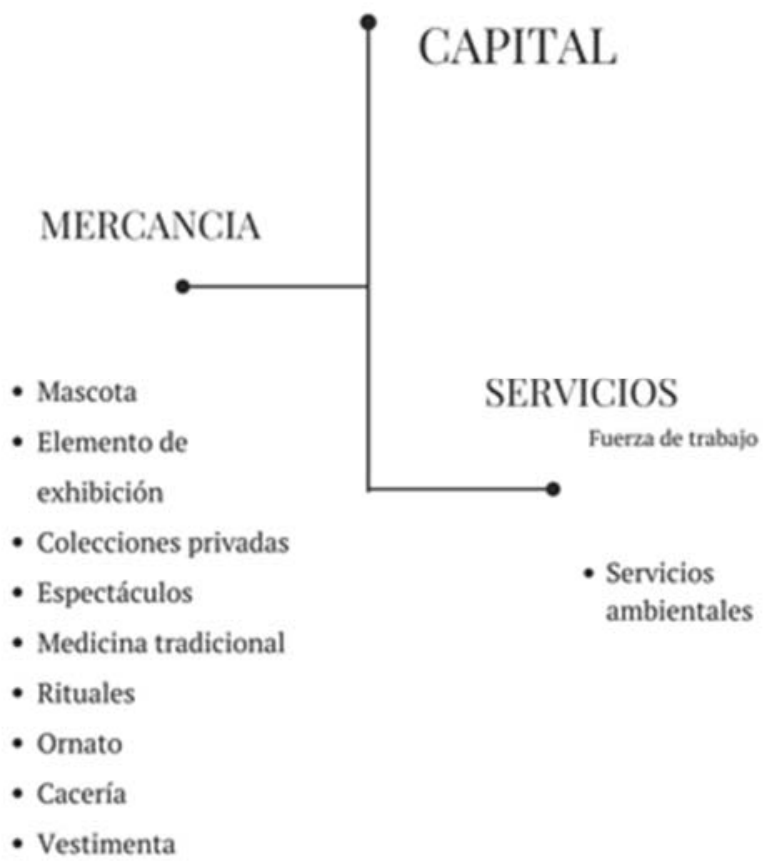

Figura 2. La cosificación del jaguar es dinámica, integral y no limitativa conforme al campo de dominación social donde interactúa. Fuente: Autoría propia.

La reducción como producto y la mercantilización del jaguar son elementos que fortalecen la cosificación perpetua del jaguar conforme al valor que tiene en la sociedad de consumo, es transformado en un elemento del capital natural y se fetichizará acorde a una modalidad de fuerza de trabajo asociado a los servicios ambientales. El jaguar en este proceso será una cosa-propiedad del capital, emergiendo como producto, servicio y mercancía de dimensiones privadas. El capital no se limita a apropiarse de la naturaleza para convertirla en mercancías, el capital rehace la naturaleza y sus productos biológica y físicamente (así como política e ideológicamente) a su imagen y semejanza, una naturaleza específicamente capitalista ${ }^{65}$. En este proceso, el jaguar como elemento de la naturaleza será conceptualizado acorde a su valor en el capital, el mecanismo impreso en esta dominación se asocia al referente ausente ${ }^{66}$, el cual separa al individuo dominador del sujeto-jaguar que está consumiendo, esto a su vez separa al sujeto-jaguar del producto final en el que se convierten las partes de su cuerpo, esto invisibiliza y elimina la violencia de dominación inherente al consumo de felinos en las sociedades de consumo, protegiendo la conciencia de las personas dominantes. La transformación de la subjetividad del sujeto-jaguar a objeto-jaguar es un movimiento de desplazamiento hacia el no ser; valoriza el producto como objeto inerte para la sociedad de consumo, esta separación total dialéctica del sujeto a objeto es la base de la asolación del jaguar.

El poder y el dominio del humano sobre el jaguar y en general de la naturaleza se sustenta en satisfacer la voracidad de las sociedades de consumo, esta dominación ha prevalecido como política del estado moderno el cual ha generado una dinámica de laissez faire et laissez passer para la acumulación del capital. Esta acción transforma y reduce al jaguar en bienes y productos que conformarán el capital natural. En esta lógica capitalista del mercado, el jaguar será transformado en una mercancía que impulsará su consumo basado en la aniquilación, destrucción y sufrimiento desde una racionalidad capitalista, generando diversos espacios de explotación y esclavitud. El absolutismo mercantil del jaguar como sistema es un orden en que la producción condicionará la destrucción de este felino.

Al racionalizar al jaguar como una cosa y un recurso que genera acumulación de capital, su vida y

\footnotetext{
${ }^{65}$ O’CONNOR, J. Causas naturales. Ensayos de marxismo ecológico (México 2001) p.281.

${ }^{66}$ Véase ADAMS C. La política sexual de la carne. Una teoría crítica feminista vegetariana (Madrid 2016). 
muerte se transforman en mercancía en una relación con el humano puramente cuantitativa ${ }^{67}$. El valor del jaguar en la modernidad se dará de acuerdo a su oferta y demanda, donde la cadena de valor genera un ciclo especista que impide por su naturaleza que el jaguar y sus defensores puedan romper esta condición de explotación. Cuando el jaguar se reduce a esclavo al servicio del capital la vida de este ser -al igual que los propietarios oprimidos- será fuerza de trabajo la que se expone ${ }^{68}$. En el esclavismo, el sujeto humano (y el jaguar) será comprado íntegra y sustancialmente como cosa, y de inmediato subsumido como determinación interna de un proceso de trabajo, en este sentido Marx señala que el obrero no es, desde que nace hasta que muere, más que fuerza de trabajo y todo su tiempo libre es tiempo de trabajo que pertenece al capital para su incrementación ${ }^{69}$; al igual que el obrero, el jaguar representa una forma similar de fuerza de trabajo para el capital, además de transformarse en mercancía.

Al fetichizar ${ }^{70}$ al jaguar se le concibe como una cosa, una mercancía o un objeto para los fines de las sociedades de consumo, esto invisiviliza el apartado ontológico del ser y la esencia de este felino como un elemento de creencias y deseos; percepción, memoria y un sentido del futuro; una vida emocional, intereses y preferencias como otros animales ${ }^{71}$. La invisibilización bajo el racionalismo del capital se manifiesta bajo formas sistematizadas y ocultas, esto hace que la explotación, la dominación y el mando despótico sobre la vida desaparezcan del horizonte de la simple vivencia y percepción ${ }^{72}$.

\section{EL ASEDIO DEL JAGUAR EN LA MODERNIDAD}

\section{LIBERACIÓN}

Ontología

Ser-Esencia

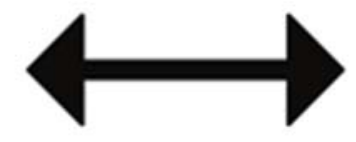

DOMINACIÓN

\section{Especismo}

Mercancia-Fetichismo

Producto

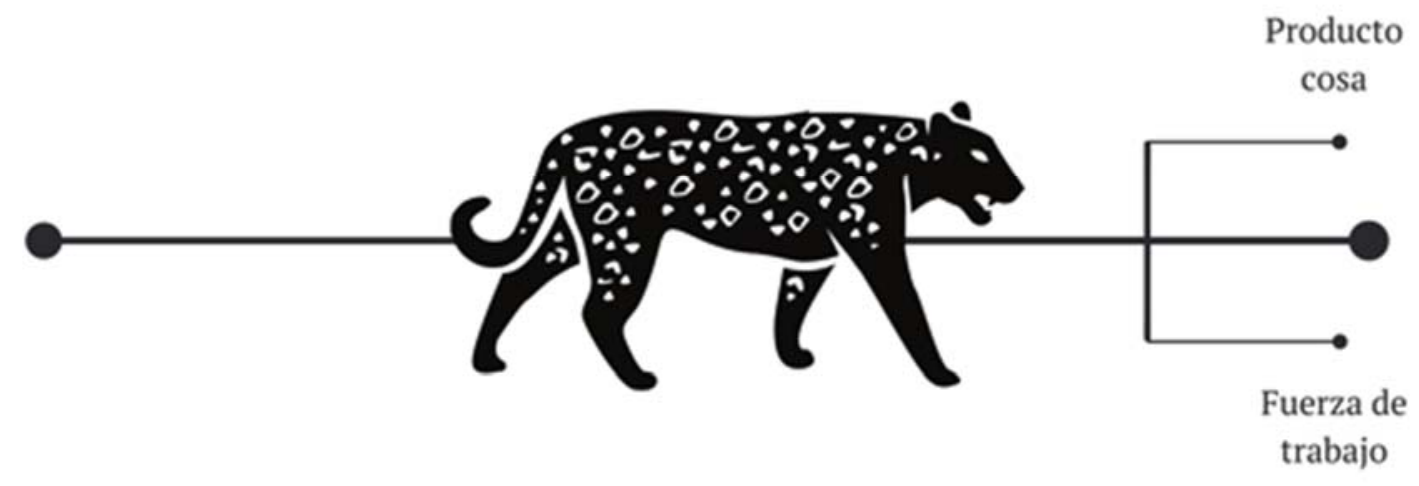

Figura 3. El asedio del jaguar en la modernidad. Fuente: Autoría propia.

En la era moderna, el capitalismo ha absorbido al jaguar, convirtiéndolo en mercancía y servicio. Esta dominación se materializa en un orden institucional en normatividades morales y jurídicas que lo consideran

\footnotetext{
${ }^{67}$ FRANDSEN, G. El hombre y el resto de los animales, en https://dialnet.unirioja.es/servlet/articulo?codigo=4736620 [Última consulta: 23 de noviembre 2020].

${ }_{68}$ OSORIO J. Biopoder y biocapital. El trabajador como moderno, en http://www.scielo.org.mx/pdf/argu/v19n52/v19n52a5.pdf [Última consulta: 23 de noviembre 2020].

${ }^{69}$ MARX, C., El Capital. Tomo I (México 2015) 185 y ss.

${ }^{70} \mathrm{El}$ fetichismo consiste en un mecanismo cognitivo por el que se oculta en una relación el momento fundamental de lo que aparece. Esto se logra al interpretar como absoluto el termino fundado o relativo de la relación, véase DUSSEL E. Hacia un Marx desconocido. Un comentario a los Grundrisse (México 1988) y DUSSEL, E. Materiales para una política de la liberación (Buenos Aires 2007).

${ }^{71}$ REGAN, T. En defensa de los derechos de los animales (México 2016) p. 240.

${ }_{72}$ OSORIO J. Biopoder y biocapital. El trabajador como moderno, en http://www.scielo.org.mx/pdf/argu/v19n52/v19n52a5.pdf [Última consulta: 23 de noviembre 2020].
} 
como un recurso al servicio del humano o un objeto que es susceptible de tener un dueño o poseedor capaz de dominar su vida. El jaguar tendrá un valor en relación al capital o será una amenaza cuando atente contra el sistema. En la actualidad, la sociedad de consumo ha instrumentado una industria cultural que destruye al jaguar, donde la muchedumbre no es creadora sino destinataria pasiva de productos y mensajes generados por los empresarios de la comunicación ${ }^{73}$. En este mundo racionalizado por el capital, la alienación absoluta impide la creación de actos para liberar al jaguar, pues todo cambio es reabsorbido por el sistema y quienes pretenden establecer una lógica ambiental de la liberación del jaguar, son arrojados a la periferia, al no saber, al anti-logos, y serán considerados irracionales por una ciencia al servicio del capital que se ha convertido en una industria ${ }^{74}$ que es resultado de una simbiosis entre ciencia aplicada y la industria en función de la productividad entendida como rentabilidad ${ }^{75}$. En su vertiente de conservación esta ciencia se sustentará en dominar, transformar y aprovechar al jaguar.

La apropiación de la vida -del jaguar- constituye un aspecto que pone de manifiesto la dimensión política del capital ${ }^{76}$, esto ha alejado la visión ontológica y ha reforzado el racionalismo especista que aún persiste en la actualidad pese a la resistencia y al racionalismo bioético-ambiental que busca liberar a esta especie.

\section{Conclusión}

La estructura de la civilización bajo el sesgo especista ha sido un eje en la aniquilación del jaguar. El declive de este felino debe de ser abordado desde dimensiones sociales a fin de entender el fenómeno de aniquilación de un orden multifactorial al cual podemos develar desde sus imbricaciones de origen en la historia del dominio del humano sobre la naturaleza, y que se maximizará en la historia moderna.

El jaguar es un ser racional, con conciencia y sistemas cognoscitivos complejos, cada individuo de esta especie se constituye como un ser en sí mismo. Estas conjeturas se sustentan en la evidencia científica que devela el ser del jaguar, que el capitalismo trata de ocultar en la fetichización. En la actualidad existe un asedio a esta especie, llevándolo a la cosificación como producto-mercancía bajo esquemas de dominio y poder. Esta cosificación y reducción se cimienta en la conquista y se consolida en la historia contemporánea principalmente en la era del capital, la era del imperio y el siglo XX.

En la actualidad, el modelo de racionalidad capitalista perpetuará la fetichización del jaguar como producto e industrializará una ciencia arcaica para la conservación del jaguar desde el especismo y el dominio, enfocándose en satisfacer la voracidad de las sociedades de consumo y no en una conservación y liberación de esta especie. La acumulación del capital a través de la reducción y transformación como producto y mercancía de este felino ha sido sanguinaria, miles de ejemplares han sido asesinados y han orillado a la extinción al jaguar, esta dimensión social de aniquilación se continúa perpetuando en la actualidad.

La asolación del jaguar en el capitalismo es el resultado del despliegue del movimiento de acumulación que busca transformar la naturaleza y la fuerza de trabajo de toda la tierra, ya que el capital no puede desarrollarse sin los medios de producción y fuerzas de trabajo en esta escala ${ }^{77}$. En el siglo XXI se han conjugado sistemas complejos de dominación, consolidando estructuras y superestructuras de la asolación del jaguar, esta dominación necesita un giro dialéctico de liberación que destruya el campo de dominación a fin de construir una sociedad libre que tenga el impulso vital de abolir los sistemas de servidumbre y esclavitud del jaguar y construir un campo basado en la liberación, y así, crear un nuevo paradigma de la conservación que nos permita reconocer a los jaguares como seres sintientes, cognoscitivos, con fines en sí mismos y no como esclavos o sujetos de explotación. Este giro dialéctico de liberación deberá resignificar al jaguar y la naturaleza desde Latinoamérica, dándole un nuevo sentido a su existencia. Los seres autoconscientes -como el jaguar- son irremplazables, son seres en el mundo, ipso facto con dignidad inherente. La ciencia y la ética de la liberación son las dos grandes esperanzas de la civilización para destruir el campo de la dominación y la aniquilación del jaguar.

\section{Bibliografía}

- ABBOTT, N. J., MADDOCK, W. y MADDOCK L. Cephalopod Neurobiology: Neuroscience

\footnotetext{
${ }^{73}$ Veáse HORKHEIMER, M. y ADORNO, T. Industria cultural en Industria cultural y sociedad de masas (Caracas 1969).

${ }^{74}$ BERNAL, J. La libertad de la necesidad (México 1958) p. 174.

${ }^{75}$ BARTRA, A. El hombre de hierro. Límites sociales y naturales del capital en la perspectiva de la Gran Crisis (México 2014) p. 49 y ss.

${ }^{76}$ OSORIO, J. Biopoder y biocapital. El trabajador como moderno, en http://www.scielo.org.mx/pdf/argu/v19n52/v19n52a5.pdf [Última consulta: 23 de noviembre 2020].

${ }^{77}$ LUXEMBURGO, R. La acumulación del capital (México 1967) y p.280 ss.

58 Derecho Animal. Forum of Animal Law Studies, vol. 12/1
} 
Studies in Squid, Octopus, and Cuttlefish. (Oxford 1995).

- ADAMS, C. La política sexual de la carne. Una teoría crítica feminista vegetariana (Madrid 2016).

- AMODIO, P. Octopus intelligence: the importance of being agnostic. https://www.repository.cam.ac.uk/handle/1810/295043 [Última consulta: 23 de noviembre 2020].

- AMODIO, P., BOECKLE, M., SCHNELl, A., OSTOJI, L., FIORITO, G. y CLAYTON, N. Grow smart and die young: why did cephalopods evolve intelligence? Trends in Ecology and Evolution 34 (2019) pp. 45-56.

- AMODIO, P., BOECKLE, M., SCHNELl, A. K., OSTOJI, L., FIORITO, G. y CLAYTON, N. S. Shell loss in cephalopods: trigger for, or by-product of, the evolution of intelligence? A reply to Mollo et al en Trends in Ecology and Evolution 34 (2019) 690-692.

- BARLOW, R. La extensión del imperio de los culhua mexica en Robert Hayward Barlow: Obra histórico-antropológica (México 2005).

- BARNOSKY, A. The late Pleistocene event as a paradigm for widespread mammal extinction en DONOVAN, S. (Ed.), Mass Extinctions: Processes and Evidence, (Columbia 1989).

- BARTRA, A. El hombre de hierro. Límites sociales y naturales del capital en la perspectiva de la Gran Crisis (México 2014).

- BERNAL J. La libertad de la necesidad (México 1958).

- BORREGO, N. Big cats as a model system for the study of the evolution of intelligence, https://www.sciencedirect.com/science/article/abs/pii/S0376635716302960 [Última consulta: 23 de noviembre 2020].

- BRASWEll, G. E., GUNN, J. D., DOMÍNGUEZ-CARRASCO, M. R., FOLAN, W. J., FLETCHER, L., MORALES-LÓPEZ, A., y GLASCOK, M. D. Defining the Terminal Classic at Calakmul, Campeche, en The Terminal Classic in the Maya Lowlands: Collapse, Transition, and Transformation, DEMAREST, A., RICE, P. M. y RICE, D. S. (eds.) (Colorado 2004).

- CABRERA, A. y YEPES, J. Mamíferos Sud-americanos. Historia Natural Ediar (Buenos Aires 1940).

- CARRASCO P. Estructura político-territorial del imperio tenochca. La Triple Alianza de Tenochtitlán, Tetzcoco y Tlacopan (México 1996).

- CARRUTHERS, P. La cuestión de los animales: teoría moral aplicada (Cambridge 1995).

- CEBAllos G., LIST, R. MEDELLÍN, R., BONACIC, C. y PACHECO, J. Los Felinos de América. Cazadores sorprendentes (México 2010).

- CEBAllos G., CHÁveZ C., RIVERA A. y MANTEROlA C. Tamaño poblacional y conservación del jaguar en la reserva de la biosfera de Calakmul, Campeche, México en El jaguar en el nuevo milenio (México 2002).

- DARWIN, C., The Descent of Man, and Selection in Relation to Sex (Princeton 1982).

- DE LA TORRE, J., GONZÁlEZ MAYA, J., ZARZA, H., CEBALlOS, G., y Medellín, R. The jaguar's spots are darker than they appear: Assessing the global conservation status of the jaguar Panthera onca en https://www.cambridge.org/core/journals/oryx/article/jaguars-spots-are-darkerthan-they-appear-assessing-the-global-conservation-status-of-the-jaguar-pantheraonca/07988F672DDB1CD701370FC3E196199E\# [última consulta: 23 de noviembre 2020] https://doi:10.1017/S0030605316001046.

- DE OlIVEIRA, T.G., RAMALHO, E. E y DE PAULA, R.C. (2012) Red List assessment of the jaguar in Brazilian Amazonia http://www.catsg.org/fileadmin/filesharing/5.Cat_News/5.3._Special_Issues/5.3.7._SI_7/de_Olivei ra_et_al_2012_Red_list_assessment_of_the_jaguar_in_Brazilian_Amazonia.pdf [Ültima consulta: 23 de noviembre 2020].

- DE ROJAS J.L. Los libros pictográficos de tributos: Códice Mendoza y Matrícula de tributos. Estudios de historia social y económica de América, 12 (1995) pp. 651-662.

- DE WAAL, F. El mono que llevamos dentro (Barcelona 2007).

- DE WAAL, F. Primates y filósofos. La evolución de la moral del simio al hombre (Barcelona 2007).

- DE WAAL, F. El Bonobo y los diez mandamientos (México 2014).

- DE WAAL, F. ¿Tenemos suficiente inteligencia para entender la inteligencia de los animales? (Madrid 2016).

- DÍAZ DEL CASTILLO, B. Historia verdadera de la Conquista de la Nueva España (Barcelona 2011).

- DILLEHAY T.D., y KAULICKE, P., Aproximación metodológica: El comportamiento del jaguar 
y la organización hocio-espacial humana http://sedici.unlp.edu.ar/bitstream/handle/10915/25133/Documento_completo.pdf?sequence=1 [Última consulta: 23 de noviembre 2020].

- DUNNING, N. P. Birth and Death of Waters: Environmental Change, Adaptation and Symbolism in the Southern Maya Lowlands, en Espacios mayas: usos, representaciones, creencias (México 2003).

- DUSSEL E. Hacia un Marx desconocido. Un comentario a los Grundrisse (México 1988).

- DUSSEL, E. 16 tesis de economía política. Interpretación filosófica (México 2014).

- DUSSEL, E. Materiales para una política de la liberación (Buenos Aires 2007).

- EHRLICH P.R. y EHRLICH A.H. The Dominant Animal. Human Evolution and Environment (Washington 2008).

- EMERY, N. J. \& CLAYTON, N. S.The mentality of crows: convergent evolution of intelligence in corvids and apes Science, 306, (2004) pp.1903-1907. https://doi.org/10.1016/j.tree.2018.10.010

- FITZGERALD, S. International Wildlife Trade: Whose Buisiness is It? (Washington DC 1989).

- FRANCES, B. Tres formas de intercambio en la economía azteca en Economía, política e ideología en el México Prehispánico (México 1980).

- FRANDSEN, M. El hombre y el resto de los animales, en https://dialnet.unirioja.es/servlet/articulo?codigo $=4736620$ [Última consulta: 23 de noviembre 2020].

- Fundación Misión Colombia, Historia de Bogotá. Conquista y Colonia, Tomo I (Colombia 1989).

- GALINDO Y VILLA, J. Códice Mendoza (México 1988).

- GERRITSEN P.R.W. y ESPARZA J. Percepciones y opiniones de campesinos y técnicos en torno al jaguar y su conservación en la Reserva de la Biosfera Sierra de Manantlán, Occidente de México. Áreas Naturales ProtegidaS, Scripta, 5 (2019) pp.19-38. DOI: 10.31840/sya.v0i7.1590

- GERRITSEN P.R.W. y ESPARZA CARLOS J.P.Percepciones y opiniones de campesinos y técnicos en torno al jaguar y su conservación en la Reserva de la Biosfera Sierra de Manantlán, Occidente de México. Áreas Naturales Protegidas Scripta, 5 (2019) pp.19-38. DOI: doi.org/10.18242/anpscripta.2019.05.05.02.0002

- GONZÁLEZ MAYA J.F. Densidad, uso de hábitat y presas del jaguar (Panthera onca) y el conflicto con humanos en la región de Talamanca, Costa Rica (Costa Rica 2008).

- GRATWICKE, B., MILlS, J., DUTTON, A., GABRIEL, G., LONG, B., SEIDENSTICKER, J., WRIGHT, B., YOU, W., ZHANG, L. Attitudes Toward Consumption and Conservation of Tigers in China. https://pubmed.ncbi.nlm.nih.gov/18596926/ [Última consulta: 23 de noviembre 2020] https://10.1371/journal.pone.0002544.

- GUGGISBERG, C.A.W. Wild cats of the world (New York 1975).

- GUNN, J.D., FOSS, J.F., DOMÍNGUEZ-CARRASCO, M.R., y FAUST, B.B., Bajo Sediments and the Hydraulic System of Calakmul, Campeche, México. https://www.cambridge.org/core/journals/ancient-mesoamerica/article/abs/bajo-sediments-and-thehydraulic-system-of-calakmul-campeche-mexico/983A4CF66394721B60708A22E436BF2A. [Última consulta 23 de noviembre 2020].

- GUNN, J.D., MATHENY, R.T. y FOLAN, W.J. Climate Change Studies in the Maya Area. https://www.researchgate.net/publication/231980445_Climate-

Change_Studies_in_the_Maya_Area [Última consulta: 23 de noviembre 2020].

- HASSIG, R. Aztec Warfare. Imperial Expansion and Political Control (Oklahoma 1995).

- HIDALGO-MIHART, M., CONTRERAS-MORENO, F., JESÚS DE LA CRUZ, A., JUÁREZLÓPEZ, R., VALERA-AGUILAR, D., PÉREZ-SOLANO, L., \& HERNÁNDEZ-LARA, C. (2015). Registros recientes de jaguar en Tabasco, norte de Chiapas y oeste de Campeche, México. Revista mexicana de biodiversidad, 86, (2015) pp.469-477. DOI: https://doi.org/10.1016/j.rmb.2015.04.019

- HORKHEIMER M. y ADORNO T.W. Industria cultural en Industria cultural y sociedad de masas (Caracas 1969).

- JOZET-ALVES, C., BERTIN, M. \& CLAYTON, N. S. (2013). Evidence of episodic-like memory in cuttlefish. https://www.sciencedirect.com/science/article/pii/S0960982213012621 [Última consulta: 23 de noviembre 2020] https://doi.org/10.1016/j.cub.2013.10.021

- JUNIUS B. BIRD. Pre-ceramic art from huaca prieta, Chicama Valley, en Nawpa Pacha: Journal of Andean Archaeology, 1 (1963) pp. 29-34.

- KURTÉN, B. 1965. The Pleistocene Jaguar in North America. Bulletin of the Florida State Museum, Biological Series, 9 (1965) pp.215-273. 
- LATHRAP D.W. The Upper Amazon (Ancient people \& places) (Londres 1970).

- LEAKEY, R. y LEWIN, R. La sexta extinción el futuro de la vida y de la humanidad (Barcelona 1997).

- LEÓN-PORTILLA, M. Religión de los nicaraos. Análisis y comparación de tradiciones culturales nahuas (México 1972).

- LEVI-STRAUSS, C. Mitologías. Lo crudo y lo cocido (México 1968).

- LÓPEZ-AUSTIN A., MILLONES, L. Dioses del norte, dioses del sur (México 2007).

- LORENZ, K. Sobre la agresión: el pretendido mal (Madrid 1972).

- LUO, S.J., JOHNSON, W.E., MARTENSON, J., ANTUNES, A., MARTELLI, P., UPHYRKINA, O., TRAYLOR-HOLZER, K., SMITH, J.L.D., y O'BRIEN, S.J. Subspecies Genetic Assignments of Worldwide Captive Tigers Increase Conservation Value of Captive Populations. https://www.sciencedirect.com/science/article/pii/S096098220800434X [Última consulta: 23 de noviembre 2020] https://doi.org/10.1016/j.cub.2008.03.053

- LUXEMBURGO, R. La acumulación del capital (México 1967).

- MARX, C. El capital. Tomo I (México 2015).

- MEGGERS, B. J., EVANS, C. Y ESTRADA E. Early Formative period of coastal Ecuador; the Valdivia and Machalilla phase, en Smithsonian Contributions to Anthropology, 1. (Washington D.C. 1965).

- MORALES A. y MORALES J. Justicia y vida silvestre: dos estudios de caso sobre ilícitos ambientales del orden federal asociados al jaguar en México. https://revistes.uab.cat/da/article/view/v9-n3-morales [Última consulta: 23 de noviembre 2020] https://doi.org/10.5565/rev/da.335

- MORALES, A y MORALES, J. Patrimonio cultural y biodiversidad; el caso del jaguar mexicano, en Boletín Mexicano de Derecho Comparado, [S.1.], pp. 973-999, june 2019. ISSN 2448-4873. $<$ https://revistas.juridicas.unam.mx/index.php/derecho-comparado/article/view/13664/15002>.
[Última
consulta
26
noviembre
2020] doi:http://dx.doi.org/10.22201/iij.24484873e.2018.153.13664.

- NOVAK, M. El capitalismo correctamente entendido la visión del humanismo cristiano. Faith and Reason, 17 (1991). https://www.cepchile.cl/cep/estudios-publicos/n-31-a-la-60/estudios-publicosn-48/el-capitalismo-correctamente-entendido-la-vision-del-humanismo-cristiano [última consulta 23 de noviembre 2020].

- NOWELL, K. y JACKSON P. Wild Cats: Status Survey and Conservation Action Plan. (Cambridge 1996).

- O’CONNOR, J. Causas naturales. Ensayos de marxismo ecológico (México 2001).

- OPARÍN, A. El origen de la vida (Madrid 1984).

- OSORIO J. Biopoder y biocapital. El trabajador como moderno. http://www.scielo.org.mx/pdf/argu/v19n52/v19n52a5.pdf [Última consulta: 23 de noviembre 2020].

- REGAN, T. En defensa de los derechos de los animales (México 2016).

- REICHEL-DOLMATOFF, G. Amazonian Cosmos (Chicago 1971).

- REICHEL-DOLMATOFF, G. El chamán y el jaguar: estudio de las drogas narcóticas entre los indios de Colombia (Bogotá 1978).

- REICHEL-DOLMATOFF, G. Excavaciones arqueológicas en Puerto Hormiga: Departamento de Bolívar. Tomo 2 (Colombia 1965).

- REICHEL-DOLMATOFF, G. Colombia indígena, periodo prehispánico en Nueva Historia de Colombia (Bogotá 1971).

- ROTH, G. (2015). Convergent evolution of complex brains and high intelligence. Philosophical Transactions of the Royal Society https://www.ncbi.nlm.nih.gov/pmc/articles/PMC4650126/ [Última consulta: 23 de noviembre 2020] https://dx.doi.org/10.1098\%2Frstb.2015.0049

- SAGAN, C. Los dragones del edén. Especulaciones sobre la evolución de la inteligencia humana (Barcelona 2002).

- SANDERSON E., CHETKIEWICZ C., MEDELLÍN, R., RABINOWITZ, A., REDFORD, K., J. ROBINSON y TABER, A. Un análisis geográfico de estado de conservación y distribución de los jaguares a través de su área de distribución en MEDELLÍN R. A., EQUIHUA, C., CHETKIEWICZ, C. L. B., CRAWSHAW JR, P. G., RABINOWITZ, A.,. REDFORD, K. H, ROBINSON, J. G., SANDERSON, E. W. y TABER, A. B. (comp.) El jaguar en el nuevo milenio (México 2002).

- SANDERSON E., REDFORE K., CHETKIEWICZ Ch., MEDELLÍN R., RABINOWITZ A.,ROBINSON K. y TABER A. Planning to save species: the jaguar as model, en Conservation 
Biology 16 (2002) pp. 58-72.

- SMITH, N.J.H. Spotted cats and the Amazon skin trade, en Oryx 13 (1976) pp.362-371.

- SOENTGEN J. Ecología del Miedo (Barcelona 2019).

- SOLLMANN, R., TÔRRES, N.M. \& SILVEIRA, L. (2008) Jaguar conservation in Brazil: the role of protected areas.https://www.researchgate.net/publication/238781533_Jaguar_Conservation_in_Brazil_The_ Role_of_Protected_Areas [Última consulta: 23 de noviembre 2020].

- TOBLER, M.W., CARRILlO-PERCASTEGUI, S.E., ZÚÑIGA, A. y POWELL, G.V.N. High jaguar densities and large population sizes in the core habitat of the southwestern Amazon. Biological Conservation, 159, (2013) pp. 375-381.

- WELLS, M. J. Octopus: Physiology and Behaviour of an Advanced Invertebrate (Londres, 1978).

- YANG, T. I. \& CHIAO, C. C. Number sense and state-dependent valuation in cuttlefish. https://www.researchgate.net/publication/307588970_Number_sense_and_statedependent_valuation_in_cuttlefish [Última consulta: $23{ }^{-} \mathrm{de}^{-}$noviembre 2020]. DOI: $10.1098 / \mathrm{rspb} .2016 .1379$

- ZAVALA, SILVIO. Los intereses particulares en la conquista de la Nueva España (México 1964).

\section{DOCUMENTO}

- Declaración Sobre la conciencia de Cambridge. https://www.animal-ethics.org/declaracionconsciencia-cambridge/ [Última consulta: 23 de noviembre 2020]. 